\title{
Production of Kenaf Fiber from Shrimp Shells Compostfor Hand Crafts with Natural Dyes
}

\author{
Rusmini Rusmini*, Daryono Daryono, Riama Rita Manullang, Dwinita Aquastini \\ State Agricultural \\ Polytechnic Institute of Samarinda \\ Samarinda, Indonesia \\ *iefira@gmail.com
}

\begin{abstract}
The production of kenaf fiber for industry mostly uses chemical fertilizers with synthetic dyes which will also cause health and environmental problems and have an adverse effect on all forms of life. Increasing awareness of health and the environment makes the production of organic kenaf fiber with natural dyes highly recommended both for handicrafts and for industrial scale because fertilizers and natural dyes are non-toxic, biodegradable, and environmentally friendly. The purpose of this study was to determine the level of consumer preference for organic kenaf fiber with natural dyes. The study used a twofactor randomized block design with the first factor of organic kenaf fiber and the second factor of natural dyes consisting of 4 levels. The study was repeated as many as 2 replications so that there were 10 experimental units. Variables observed in the level of consumer preference for handicraft products from organic kenaf fiber with natural dyes which include colour, texture and odor are tested. This test was carried out by the Hedonic Test method, using a questionnaire with 40 untrained (consumer) panellists with data obtained based on panellist responses using the hedonic scale analysed by the Kruskal-Wallis test. The results showed that there were no significant differences in the level of consumer preference for colour, texture and odor from organic kenaf fibers with various natural dyes.
\end{abstract} nut

Keywords—kenaf, turmeric, suji leaf, dragon fruit skin, areca

\section{INTRODUCTION}

Kenaf is a type of plant that is easily cultivated in tropical regions such as Indonesia. Kenaf is very potential for industry globally because of its high cellulose content. The content of natural fiber generally consists of cellulose, hemicellulose, and lignin. Cellulose from natural fibers has a structure arranged in micro-fibrils surrounded by two main components, namely: hemicellulose and lignin. Producing organic kenaf fiber which has the best holosellulose content in kenaf fiber which is $81.2800 \%$ and the best cellulose content is $40.5695 \%$ [1]. Organic kenaf fiber is a kenaf fiber that is produced from the stem of the kenaf plant that has gone through various stages both in terms of fertilization and pest control carried out organically and in terms of bonding activities, generally kenaf fiber is yellowish white and used as raw material in diversified products, such as: paper, wall coatings, car interiors, geotextiles, soil safers, fiber drains, particle boards, and plastic reinforcement and raw materials for the biofuel industry. The colouring process is needed to make the appearance of organic kenaf fibers more attractive to consumers and high-selling power. Synthetic colouring materials are commonly used in fiber colouring because they are easier to use. Synthetic dyes have several advantages compared to natural dyes, which are, among others, easily available on the market, availability of guaranteed colours, various types of colours and more practical and easier to use [2,3] and more economical [4] and cheaper $[3,5]$. Besides synthetic dyes, more stable, more resistant to various environmental conditions, the colouring power is stronger and has a wider colour range [3] and is not easily faded and brightly coloured [6]. Synthetic dye waste can cause environmental pollution and is a hazardous material, because some dyes can be degraded into carcinogenic and toxic compounds [6,7]. Furthermore, Kant stated that textile industry waste is full of colour and organic chemicals from synthetic dyes [6]. Mixing colloidal material with dye waste, can increase turbidity and make the water look bad, smelly, prevent the penetration of sunlight. The impact is the depletion of dissolved oxygen, decreasing water quality and the death of living things that live in it due to lack of oxygen or contaminated with toxic compounds [7]. In addition, when waste is allowed to flow, it will clog pores, which results in loss of soil productivity, hardened soil texture and prevents penetration of plant roots [6].

The advantage of using natural dyes is because they have high economic value and selling value and are environmentally friendly. Textile colours that use natural colours are more distinctive and soft compared to synthetic colours so that they have a high aesthetic value. Although the use of natural dyes has several disadvantages compared to synthetic dyes, it still continues to be used today [8]. Natural dyes have been recommended as dyes that are friendly to both the environment and health because their natural component content has a relatively low pollution load, easily biodegradable and nontoxic [9].

Plants that are used as dyes can be obtained around our environment so that they are cost-effective. The advantages of natural dyes include, the colours produced are very varied and unique, the colours tend towards soft, the intensity of the colour of the cornea is very soothing that it will nourish the eyes, and contain antioxidants so that it is comfortable and safe when used by humans [10]. Fashion designs that use natural 
dyes have a high selling value or economic value because they have distinctive art and colour values, are environmentally friendly so that they have ethnic and exclusive impressions.

As an effort to revive the use of natural dyes for textiles, we need a source of dyes from the potential of existing natural resources, continuous and continuous availability, stable production of raw materials, and not seasonal products, including suji leaves, turmeric and dragon fruit peels.

Thus the researchers are interested in examining the use of natural dyes against organic kenaf fiber to the level of consumer preference.

\section{MATERIAL AND METHODS}

The research was carried out at the production and chemical laboratory analysis of forestry crops in the Samarinda State Agricultural Polytechnic from February to August 2018.

\section{A. Tools and Materials}

The tools used are 101 jars, knives, cutting boards, scissors, scales, blenders and cloth filters, glass funnels, measuring cups, rock collisions, grated coconut and stirrers while the ingredients used are $4 \mathrm{~kg}$ of organic kenaf fiber, suji leaves, turmeric, and dragon fruit skin, filter paper, raffia and water.

\section{B. Experimental Design}

This experiment is a factorial study consisting of 2 factors, carried out using a Randomized Block Design. The first factor of the best compost in 2017 from shrimp skin + pesnab (K) which consists of 1 level, namely:

- $\mathrm{k} 1=$ The provision of compost as much as 30 tons ha-1 or $3 \mathrm{~kg} / \mathrm{plot}$ and the provision of vegetable pesticides as much as $100 \mathrm{ml} / \mathrm{plant}$.

The second factor is natural dyes consisting of 5 levels, namely:

- $\rho 1=$ Suji Leaf

- $\rho 2=$ Turmeric

- $\rho 3=$ Dragon fruit skin

- $\rho 4=$ Young areca nuts

- $\rho 5=$ Old areca nut

Each study was repeated 2 replications so that there were 10 experimental units.

\section{Making Natural Dyes Extract}

The process of making natural colouring extracts refers to Pringgenies, et al [11] and modifications have been made.

\section{Making Suji Natural Leaf Extract}

Fresh suji leaves are cut into small pieces with scissors then weighed $4 \mathrm{~kg}$ each and then washed, then the suji leaf is pounded to reveal the size then blended gradually with a dilution of 51 for $1 \mathrm{~kg}$ of suji leaves so that the total water added is 201 then filtered with a cloth filter followed by using filter paper so that the dye solution is completely homogeneous, for replication 1 and for replication 2 it is done like a repeat 1 then both of them are inserted into the jar as suji leaf dye for replications 1 and 2 .

\section{E. Making Turmeric Natural Dyes Extract}

Turmeric is peeled clean then weighed as much as $4 \mathrm{~kg}$, then washed thoroughly then clean turmeric is grated using grated coconut until it is completely smooth, then 201 of water is added gradually then filtered with a cloth filter followed by filter paper so that the dye solution was completely homogeneous, for replication 1 and for replication 2 it was carried out like a repeat 1 then both of them were inserted into the jar as suji leaf dye for replications 1 and 2 .

\section{F. Making Natural Dyes Extract of Dragon Fruit Skin}

The dragon fruit is peeled clean then the skin is weighed as much as $4 \mathrm{~kg}$, then washed thoroughly then the clean dragon fruit skin is cut into small pieces with the next scissors then blended gradually with water taken from 201 of water gradually then filtered with a filter. The cloth is continued by using filter paper so that the dye solution is completely homogeneous, for replication 1 and for replication 2 it is carried out like a repeat 1 then both of them are inserted into the jar as suji leaf colouring for replications 1 and 2 .

\section{G. Soaking Organic Kenaf Fiber with Suji Leaf Coloring}

Organic kenaf fiber is weighed as much as $1 \mathrm{~kg}$ for replications of 1 and $1 \mathrm{~kg}$ as well as for replications 2 , then organic kenaf fibers are soaked in the natural colouring of suji leaves that have been put into the jar. To avoid the kenaf fiber from appearing on the surface / not submerged, it is given a weight in the form of a cleaned stone that is given a white plastic to keep the plastic from affecting the bath. Then the jar was closed tightly for 3 days.

\section{H. Soaking Organic Kenaf Fiber with Turmeric Coloring}

Organic kenaf fiber is weighed as much as $1 \mathrm{~kg}$ for replications of 1 and $1 \mathrm{~kg}$ as well as for replications 2 , then organic kenaf fibers are soaked in the natural colouring of suji leaves that have been put into the jar. To avoid the kenaf fiber from appearing on the surface / not submerged, it is given a weight in the form of a cleaned stone that is given a white plastic to keep the plastic from affecting the bath. Then the jar was closed tightly for 3 days.

\section{Soaking Organic Kenaf Fiber with Dragon Fruit Skin Coloring}

Organic kenaf fiber is weighed as much as $1 \mathrm{~kg}$ for replications of 1 and $1 \mathrm{~kg}$ as well as for replications 2 , then organic kenaf fibers are soaked in the natural colouring of suji leaves that have been put into the jar. To avoid the kenaf fiber from appearing on the surface / not submerged, it is given a weight in the form of a cleaned stone that is given a white plastic to keep the plastic from affecting the bath. Then the jar was closed tightly for 3 days. 


\section{J. Making Natural Betel Seed Extract}

Betel nuts are peeled clean then the seeds are weighed as much as $4 \mathrm{~kg}$, then washed thoroughly then the clean seeds are crushed until smooth then blended gradually with the water taken from 201 of water gradually then filtered with a cloth filter followed by boiling the extract young areca nut seeds boiled for 2 hours with the heat of the stove being then cooled. The cooled decoction results can already be used for kenaf fiber dyes. The results of the decoction are then filtered again using filter paper so that the dye solution is completely homogeneous, for replication 1 and for replication 2 it is carried out like a repeat 1 then both of them are inserted into the jar as colouring for young areca nuts for replications 1 and 2 .

\section{K. Making Natural Betel Seed Extract}

Betel nuts are peeled clean then the seeds are weighed as much as $4 \mathrm{~kg}$, then washed thoroughly then the clean seeds are crushed until smooth then blended gradually with the water taken from 201 of water gradually then filtered with a cloth filter followed by boiling the extract old areca nuts boiled for 2 hours with the heat of the stove being then cooled. The cooled decoction results can already be used for kenaf fiber dyes. The results of the decoction are then filtered again using filter paper so that the dye solution is completely homogeneous, for replication 1 and for replication 2 it is carried out like a repeat 1 then both of them are inserted into the jar as an old areca nut dye for replications 1 and 2 .

\section{Kenaf Fiber Drying}

After the immersion process for 3 days, the organic kenaf fiber soaked with natural dyes according to the treatment was immediately lifted and drained, then organic kenaf fiber dikat with raffia rope to hang and dry for 10 days in the room without being exposed to sunlight to avoid the influence of ultra-rays violet from sunlight.

Observation Parameters observed included the level of consumer preference for handicraft products from organic kenaf fiber with natural dyes which included the colour, texture and odor of the fiber product being tested. This test was carried out using the Hedonic Test method, using 40 quizers with untrained panelists (consumers).

\section{Data Analysis}

Data were tested by Hedonic Test method, using 40 quizers with untrained panelists (consumers). Data obtained based on panellist responses using the hedonic scale were analysed by the Kruskal-Wallis test. Questionnaire with a rating scale very like: 7, likes: 6, rather likes: 5, neutral / normal: 4, somewhat dislikes: 3, dislikes: 2 and very dislikes: 1

\section{RESULTS AND DISCUSSION}

Organoleptic Level of Passion against Colour, Texture and Aroma Colour is a perception that arises in the human brain when looking at reflections from light in an object. Colour is influenced by the physical and chemical composition of an object, the reflected light, and the sensitivity of one's eyes [12]. Colour is one of the main attractions, and is an important criterion for the acceptance of products such as textiles, cosmetics, food and others. Dyestuffs are needed to add artistic value and are used to vary a product [13]. Colour is the first impression the panellist catches before recognizing other stimuli. Colour is very important for each product so an attractive colour will affect consumer acceptance. Based on the results of the Kruskal-Wallis analysis on the level of consumer preference for colour shows an effect that is not significantly different. Table of the average value of the level of consumer preference for the colour of organic kenaf fibers can be seen in Table 1 below:

TABLE I. AVERAge VAlue OF CONSUMER PREFERENCE FOR ORGANIC KENAF FIBER COLOR

\begin{tabular}{|c|c|c|c|c|c|}
\hline \multirow{2}{*}{$\begin{array}{c}\text { Organic } \\
\text { Kenaf } \\
\text { Fiber } \\
(\mathbf{K}) \\
\end{array}$} & \multicolumn{5}{|c|}{ Natural Dyes } \\
\hline & $\begin{array}{c}\text { Suji } \\
\text { leaf }\left(\rho_{1}\right)\end{array}$ & $\underset{\left(\rho_{2}\right)}{\text { Turmeric }}$ & 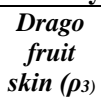 & $\begin{array}{c}\text { Young } \\
\text { areca } \\
\text { nut }\left(\rho_{4}\right)\end{array}$ & $\begin{array}{c}\text { Old } \\
\text { areca } \\
\text { nut }\left(\rho_{5}\right)\end{array}$ \\
\hline $\mathrm{K}_{1}$ & 5,46 & 5,10 & 5,16 & 5,55 & 5,10 \\
\hline
\end{tabular}

Observations from the questionnaire results can be seen the highest average colour of young areca nut with 5.55 (including a rather like value scale) while those on turmeric and old areca nut are 5.10 (including a rather like value scale) and dragon fruit skin with a value 5.16. Although not significantly different from the others.

Based on the organoleptic test using Kruskal-Wallis analysis on the level of consumer preference in colour, it was shown that natural dyes (suji leaves, turmeric, dragon fruit skin, young brood beans and old areca nut) had no significant effect on the level of consumer preference. This means that each type of natural dye gives the same effect on everyone's preference for organic kenaf fiber colours.

There were no significant differences between the first factor, namely the combination of (composting and pesticide administration) with the second factor, namely natural colouring (suji leaf, turmeric, dragon fruit skin, young brood bean and old areca nut) on the colour of kenaf fiber but from the results questionnaires show that the average panellist is rather like (5) even close to like the five natural dyes. This shows that the panelists rather like natural dyes in organic kenaf fibers even though they do not use mordan as an ingredient to increase the brightness of colours because researchers want everything to be completely natural or organic. This is in line with the research of Utami and Anjani [14] which states that the average level of consumer preference likes soursop leaf natural dyes on Mori cloth and is supported also by the study of Hidayati, et.al (2016) which states that the natural colouring of Rhizophora mangrove leaves mucronata is preferred by consumers $(46.67 \%)$ in batik cloth.

The colour of organic kenaf fiber is not statistically different from this because in the organoleptic test the natural dyes are relatively the same so the panelists cannot distinguish the colours of the organic kenaf fibers. This is presumably because panelists are not very familiar with organic kenaf fiber with natural dyes compared to synthetic dyes, this is in line with the research of Pranoto [15] which states that the colour 
organoleptic test with alum and quicklime fixators showed results that had no significant effect on natural dyes from papaya leaves. The results of this study are different from those of Anzani et al. [16] which states that natural dyes with soursop leaves with mordan or alum fixators showed significantly different results from other fixators with the best fixators are alum fixators.

The colour produced from the natural dyes of suji leaves, turmeric, dragon fruit skin, young brood seeds and old areca nut is included in the medium category visually because in this study do not use mordan which has a function as a colour generator in colouring cloth with natural dyes. This is in line with Prastyaningtyas's research [17], the results of research which dyed shantung fabric with soursop leaf extract and turmeric extract dye without using mordan also produced a medium-sized colour. The use of mordan can also add a chromophore group in fiber which causes aging of the dyed colour to be older when compared to the results of dyes without using mordan. This is supported also by the research of Zheng et al. [18] which states that proving that the soil will become an environmentally friendly natural mordan in the natural dyeing of hemp while Pawar et al. [19] stated that chemical modification of natural dyes from areca nut can be used to overcome the limitations of natural dyes such as poor strength, lack of reproducibility due to varying purity and inferior fastness properties for large-scale applications without the presence of mordan.

\section{A. Texture}

Texture or level of smoothness is also important in fiber or fabric. Based on the results of the Kruskal-Wallis analysis on the level of consumer preference for textures shows an effect that is not significantly different. The average table of consumer preference levels on organic kenaf fiber texture can be seen in Table 2 below:

TABLE II. AVERAGE VALUE OF CONSUMER PREFERENCE FOR ORGANIC KENAF FIBER TEXTURE

\begin{tabular}{|c|c|c|c|c|c|}
\hline \multirow[b]{2}{*}{$\begin{array}{c}\text { Organic } \\
\text { Kenaf } \\
\text { Fiber } \\
\text { (K) }\end{array}$} & \multicolumn{5}{|c|}{ Natural Dyes } \\
\hline & $\begin{array}{c}\text { Suji } \\
\text { leaf }\left(\rho_{1}\right)\end{array}$ & $\begin{array}{c}\text { Turmeric } \\
\left(\rho_{2}\right)\end{array}$ & 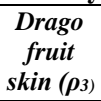 & $\begin{array}{c}\text { Young } \\
\text { areca } \\
\text { nut }\left(\rho_{4}\right)\end{array}$ & $\begin{array}{c}\text { Old } \\
\text { areca } \\
\text { nut }\left(\rho_{5}\right)\end{array}$ \\
\hline $\mathrm{K}_{1}$ & 4,51 & 4,28 & 4,55 & 5,53 & 5,48 \\
\hline
\end{tabular}

There were no significant differences between the first factor, namely the combination of (composting and giving pesticides) with the second factor of natural dyes, namely dyes from suji leaves, turmeric, dragon fruit peel, young brood seeds and old areca nuts on kenaf fiber texture.

Based on the results of the analysis that has been obtained in terms of kenaf fiber texture, there is no difference in the level of consumer preference between the combination of the first factor (giving compost and giving pesticides) with the second factor of natural colouring (natural colouring of suji leaf, turmeric, skin of dragon fruit, young seed and old areca nut). This means that each type of natural colouring gives the same effect to everyone's preference for the texture of organic kenaf fiber with natural dyes.

There were no significant differences between the first factor, namely the combination of (composting and pesticide administration) and the second factor was the natural colouring of suji leaf, turmeric, dragon fruit skin, young areca nut and old areca nut seeds on kenaf fiber texture but Table 2 shows that the average panellist is neutral / ordinary (4) and is rather like (5) to the texture of the organic kenaf fiber given natural dyes.

The texture of organic kenaf fiber with natural dyes is not statistically different from this because in the organoleptic test of natural dyes the texture of organic kenaf fibers is relatively the same so the panelists cannot distinguish the texture of the organic kenaf fibers. This is presumably because panelists are not very familiar with the texture of organic kenaf fiber with natural dyes compared to synthetic dyes and other types of fiber such as batik cloth, mori cloth and linen. This is in line with the research of Pranoto [15] which states that organoleptic tests of subtlety / texture levels with alum and fixator lime showed results that did not significantly affect the natural colouring of papaya leaves.

\section{B. Smell}

Smell is one of the factors that determine a person's preference for a food. Odor can provide a perception of a particular taste in a food [20]. Odor is used as one of the test standards for organic kenaf fibers which are coloured with natural dyes because the resulting odor of natural dyes has a distinctive odor from each natural colouring agent.

Based on the results of the Kruskal-Wallis analysis on the level of consumer preference for smells, the effect is not significantly different. Table of the average level of consumer preference for organic kenaf fiber odor can be seen in Table 3 below:

\section{TABLE III. AVERAGE VAlue of CONSUMER PREFERENCE FOR THE SMELl OF ORGANIC KENAF FIBER}

\begin{tabular}{|c|c|c|c|c|c|}
\hline $\begin{array}{c}\text { Organic } \\
\text { Kenaf } \\
\begin{array}{c}\text { Fiber } \\
\text { (K) }\end{array}\end{array}$ & $\begin{array}{c}\text { Suji } \\
\text { leaf }\left(\boldsymbol{\rho}_{1}\right)\end{array}$ & $\begin{array}{c}\text { Turmeric } \\
\left(\boldsymbol{\rho}_{2}\right)\end{array}$ & $\begin{array}{c}\text { Drago } \\
\text { fruit } \\
\text { skin }\left(\rho_{3}\right)\end{array}$ & $\begin{array}{c}\text { Young } \\
\text { areca } \\
\text { nut }\left(\boldsymbol{\rho}_{4}\right)\end{array}$ & $\begin{array}{c}\text { Old } \\
\text { areca } \\
\text { nut }\left(\boldsymbol{\rho}_{5}\right)\end{array}$ \\
\hline $\mathrm{K}_{1}$ & 4,29 & 4,59 & 4,28 & 4,88 & 4,53 \\
\hline
\end{tabular}

There were no significant differences between the first factor, namely the combination of (composting and giving pesticides) with the second factor, namely natural dyes from suji leaves, turmeric, dragon fruit peels, young brood seeds and old areca nuts to the smell of kenaf fiber.

Based on the results of the analysis that has been obtained in terms of kenaf fiber odor, there is no difference in the level of consumer preference between the combination of the first factor (giving compost and giving pesticides) with the second factor (suji leaf natural colouring, turmeric and dragon fruit skin). This means that each type of natural dye gives the same effect on everyone's preference for the smell of organic kenaf 
fiber with suji leaf natural colouring, turmeric and dragon fruit skin.

Table 3 shows that the average panellist is neutral / normal (4) to the smell of organic kenaf fiber given natural dyes.

The smell of organic kenaf fiber with natural dyes is not statistically different from this because in the organoleptic test of natural dyes the smell of organic kenaf fiber is relatively the same so the panelists cannot distinguish the smell of organic kenaf fiber. This is presumably because the panelists are not familiar with the smell of organic kenaf fiber with suji leaf natural colouring, turmeric, and dragon fruit skin compared to synthetic dyes and other types of fiber such as shantung, mori and batik and linen. This is in line with the study of Pranoto [15] which states that the odorous organoleptic test with alum and quicklime fixators showed results that had no significant effect on the natural colouring of papaya leaves on linen.

\section{CONCLUSION AND SUGGESTION}

Based on the research that has been carried out, it can be concluded that there is no significant difference in the level of consumer preference for colour, texture and odor from organic kenaf fiber with various natural dyes (suji leaves, turmeric, dragon fruit peels, young brood seeds and old areca nuts) but from the results of the percentage level of consumer preference

Stated that the panelists on average liked the colour, texture and smell of organic kenaf fibers with natural dyes.

\section{ACKNOWLEDGMENT}

Authors wish to thank Ministry of Research, Technology, and Higher Education for providing the Competitive Research Grants 2017 and 2018 that funded this study. Authors also thank Head of P2M Unit, State Agricultural Polytechnic Institute of Samarinda and all parties that helped the completion of this research.

\section{REFERENCES}

[1] Rusmini, R.R. Manullang, and Daryono, "The chemical content of Serat Kenaf from Shrimp Skin Compost with Vegetable Conch Pesticides," Journal of Tropical Forests, vol. 5, no. 1, 2017.

[2] I.W. Suarsa, P. Suarya, and I, Kurniawati, "Optimization of Types of Solvents in the Extraction of Natural Dyes from Kepok Banana Stems (Musa paradiasiaca L. CV Kepok) and Banana Milk Stems (Musa paradiasiaca L. cv milk)," Journal of Chemistry, vol. 5, no. 1, pp. 72-80, 2011.

[3] B. Kartina, T. Ashar, and W. Hasan, "Characteristics of Traders, Sanitation Processing and Rhodamin B Content Analysis on Milled Chili
Seasoning in Medan Baru District Traditional Market 2012," Environment and Occupational Health, vol. 1,no. 2, pp. 1-7, 2013.

[4] M.A.J. Purnomo, "Substances of Natural Dyes as an Alternative to Dyestuffs that are Environmentally Friendly," Journal of STSI Fine Arts Surakarta, vol. 1, no. 2, pp. 57-61, 2004.

[5] Paryanto, A. Purwanto, E. Kwartiningsih, and E. Mastuti, "Making Natural Dyes in Powder Forms to Support the Batik Industry in Indonesia," Process Engineering Journal, vol. 6,no. 1, pp. 26-29, 2012.

[6] R. Kant, "Textile Dyeing Industry an Environmental Hazard," Natural Science, vol. 4, no. 1, 2012.

[7] E. Widjajanti, P. Regina Tutik, and M.P. Utomo, "Zeolite Adsorption Patterns Against Coloring of Azyl Methyl and Methyl Orange,' Proceeding National Seminar on Research, Education and Application of MIPA, 2011.

[8] A.K. Samanta and P. Agarwal, "Application of natural dyes on textiles," Indian Journal of Fiber \& Textile Research, vol. 34, pp. 384-399, 2009.

[9] N. Rungruangkitkrai and R. Mongkholrattanasi, "Eco-Friendly of Textiles Dyeing and Printing with Natural Dyes," RMUTP International Conference: Textiles \& Fashion, 2012.

[10] S.S. Sangita and P. Satsangi, "Sesbania Aculeata: A Plant for Coloring Cotton and Silk," International Journal of Emerging Technology and Advanced Engineering, vol. 4, issue 10, pp. 141-145, 2014.

[11] D. Pringgenies, E. Supriyantini, R. Azizah, R. Hartati, Irwani, and O.K. Radjasa, Coloring Application of Mangrove Natural Materials for Batik Materials as a Diversification of Businesses in Fostered Villages in Semarang Regency, Semarang: Department of Marine Sciences \& MSDP, 2012.

[12] H.T. Lawless, H. Hildegarde, Sensory Evaluation of Food, Principles and Practice, 2010.

[13] B. Jos, P.E. Setyawan, and Y. Satia, "Optimization of Extraction and Stability Test of Phycocyanin from Microalgae (Spirulina platensic)," ENGINEERING, vol. 33, no. 3, pp. 187 -192, 2011.

[14] W.W. Utami and G. Anjani, Yogurt Daun Katuk Sebagai Salah Satu Alternatif Pangan Berbasis Laktogenik, Semarang: Diponegoro University, 2016.

[15] D. Pranoto, M.A.W. Purwanto, and R. Simanjutak, Natural Colorings of Papaya Leaves (Carica papaya. L) for Linen Fabrics Malang: Universitasy of Brawijaya, 2017.

[16] S.D. Anzani, M.H.P. Wignyanto, and S.R. Lutf, "Natural Colorings of Soursop Leaves (Annona muricata L.) for Primissima Mori Cloth (Study: Type and Concentration of Fixation)," Industria: Journal of Technology and Agroindustry Management, vol. 5, no. 3, pp. 132-139, 2016.

[17] W. Prasetyaningtyas, "Dyeing of Shantung Fabric with Soursop Leaf Extract and Turmeric Rhizome," Teknobuga, vol. 1, no. 2, 2014.

[18] G.H. Zheng, H.B. Fu, and G.P. Liu, "Application of rare earth as mordant for the dyeing of ramie fabrics with natural dyes," Korean $\mathrm{J}$. Chem. Eng., vol. 28, no. 11, pp. 2148-2155, 2011.

[19] A.B. Pawar, S.P. More, and R.V. Adivarekar, "Dyeing of polyester and nylon with semi-synthetic azo dye by chemical modification of natural source areca nut," Natural products and bioprospecting, vol. 8, no. 1, pp. 23-29, 2018.

[20] B. Kartika, Sensory Test Guidelines for Food Materials, Yogyakarta: UGM PAU. Food and Nutrition, 1988. 